\section{MANEJO EMPÍRICO DE LAS ADICCIONES EN EL PERÚ}

\section{EMPIRICAL MANAGEMENT OF ADDICTIONS IN PERU}

\author{
Ayar Nizama-Vía ${ }^{1, a}$, Martín Nizama-Valladolid,3,b
}

Sr. Editor. Ha indignado a la sociedad la muerte de treinta pacientes en un centro de rehabilitación clandestino ${ }^{(1)}$. Esta tragedia ha develado un grave problema de salud pública: nuestra incapacidad, como país, para el manejo responsable de las adicciones. El Estado y la sociedad peruana rehúyen el problema por prejuicios y tabúes, en lugar de implementar la ayuda médica necesaria. Existe una percepción banal de la adicción, valorada de manera moralista como un vicio y no como una enfermedad que requiere atención médica especializada de cobertura masiva. Actualmente, existe en el país más de un millón de adictos ${ }^{(2)}$, la mayoría sin tratamiento.

De otro lado, la clase política, y los medios de comunicación, desconocen que el adicto carece de conciencia de enfermedad y que se encuentra enfermo de la voluntad. Más del $98 \%$ de adictos rechazan cualquier forma de tratamiento; es decir, menos del $2 \%$ acepta ayuda voluntariamente ${ }^{(3)}$. Más aun, el adicto arruina la vida de su familia, principal víctima de la adicción. Sin embargo, se piensa que el adicto debe poner su voluntad, que no es un problema familiar y que la adicción no tiene curación. Además, los médicos no pueden indicar el internamiento involuntario, ya que la Ley $\mathrm{N}^{\circ} 29737$ no está reglamentada. Así, se impide a la familia autorizar el internamiento cuando es clínicamente necesario. Esta realidad crea una situación crítica: enfermos que no quieren curarse, familias que claman ayuda y médicos legalmente impedidos.

Este vacío legal es llenado por acciones empíricas y mercantilistas, realizadas por autodenominados "exadictos" quienes enmascaran sus "centros" utilizando denominaciones de fachada como: "comunidad cristiana", "evangélica", "terapéutica" o "centro de rehabilitación". Emplean frases falaces como: "solo un exadicto cura a un adicto", "la adicción es incurable" o "el médico te hace adicto a las 'pepas' (pastillas)". Emplean procedimientos sin fundamento científico

\footnotetext{
1 Sociedad Científica de Estudiantes de Medicina de la Universidad Peruana de Ciencias Aplicadas (SOCIEMUPC), Escuela de Medicina, Universidad Peruana de Ciencias Aplicadas. Lima, Perú.

2 Facultad de Medicina, Universidad Peruana Cayetano Heredia. Lima, Perú.

3 Facultad de Medicina Humana, Universidad Nacional Mayor de San Marcos. Lima, Perú

a Estudiante de Medicina; ${ }^{\mathrm{b}}$ médico psiquiatra, doctor en Medicina.
}

Recibido: 16-02-12 Aprobado: 07-03-12 como: rituales, y maltratos físicos o psicológicos. Con relativa frecuencia, dichos "centros" sirven como focos de consumo y los adictos reingresan reiteradamente.

Es importante señalar que no hay evidencia que sustente la eficacia de las comunidades terapéuticas frente a otras formas de tratamiento (4); por el contrario, desde 1990 existe registro de casos de tortura y muerte en estos supuestos centros de rehabilitación ${ }^{(5)}$. Entonces, el remedio resulta peor que la enfermedad; pues estas "terapias" pueden terminar por agravar los casos o acabar con la vida de los enfermos.

Por lo expuesto, debemos: entender las adicciones como un problema de salud pública y adoptar una política de Estado, fortaleciendo las instituciones médicas que tratan la enfermedad, identificar y clausurar definitivamente centros clandestinos, con penalidad para los infractores y promover la salud mental y la prevención familiar de las adicciones.

El Estado debe realizar un diagnóstico real y abordar terapéuticamente el problema con la fuerza ética de la medicina, pues con la ayuda de la ciencia médica el adicto sí tiene curación.

\section{Conflictos de Interés}

Los autores declaran no presentar conflictos de interés.

\section{REFERENCIAS BIBLIOGRÁFICAS}

1. Perú, Diario oficial "El Peruano". Pide que comunidades terapéuticas se formalicen [Internet]. Lima: El Peruano; c2012 [citado el 5 de febrero de 2012]. Disponible en:http:// www.elperuano.pe/Edicion/noticia-pide-comunidadesterapeuticas-se-formalicen-36449.aspx

2. Comisión Nacional para el Desarrollo y Vida sin Drogas (DEVIDA). II Encuesta Nacional de Prevención y Consumo de Drogas 2002. Lima, Perú; DEVIDA; 2003.

3. Substance Abuse and Mental Health Services Administration. Results from the 2009 National Survey on Drug Use and Health: Volume I. Summary of National Findings [Internet]. Rockville, MD: SAMHSA; 2010 [citado el 5 de febrero de 2012]. Disponible en: http://www.gmhc. org/files/editor/file/a pa nat drug use survey.pdf

4. Fiestas F, Ponce J. Eficacia de comunidades terapéuticas en el tratamiento de problemas relacionados con uso de sustancias psicoactivas: una revisión sistemática. Lima: INS-UNAGESP; 2011

5. Perú, Diario oficial "El Peruano". Entre la adicción y el olvido [Internet]. Lima: El Peruano; c2012 [citado el 3 de febrero de 2012]. Disponible en: http://www.elperuano.pe/ edicion/noticia-entre-adiccion-y-olvido-36419.aspx

Correspondencia: Martín Nizama Valladolid

Dirección: Alfredo Salazar 314, Of. 303, Lima 27, Perú. Teléfono: (511) 421-9939 Anexo 430 y 433 / 999-836040.

Correo electrónico: maniva@terra.com.pe 